\title{
Política y lucha de partidos en la Huelva de la Restauración: las elecciones a Cortes de 1919
}

\author{
Juan Carlos de lara Ródenas*
}

\section{PALABRAS INICIALES}

Como nos recuerda Javier Tusell en Oligarquía y caciquismo en Andalucia (1890-1923), obra fundamental para conocer los entresijos de la política andaluza de principios de siglo, en la situación en la que se encontraba el sistema de la Restauración a la altura de 1919, y "vista la carencia de posibilidades de evolución, el advenimiento de la Dictadura de Primo de Rivera no tiene nada de sorprendente" ' ${ }^{1}$. Reconocida la importancia -por incapacidad e inercia- de estos años sombríos que siguen al estallido renovador de 1917 en el establecimiento de la dictadura y la definitiva disolución del sistema, fácil será admitir que cualquier estudio sobre la política y los políticos de este momento puede resultar realmente enriquecedor. Cuánto más si tenemos en cuenta la parquedad de análisis locales sobre las élites de este período concreto.

Por otra parte, está fuera de toda duda la decisiva importancia que la vida política y los mecanismos electorales de provincias están alcanzando, en las actuales investigaciones, para comprender, matizar y valorar en su justa medida la gran maquinaria política de la Restauración. La

* Universidad de Sevilla.

1 Tusell GomeZ, Javier, Oligarquía y caciquismo en Andalucia (1890-1923). Barcelona, Edit. Planeta, 1976, pág. 565. 
tendencia a circunscribir el estudio en las cimas de la política española es algo que va alejándose, progresivamente, de las modernas investigaciones sobre el período. La Restauración no está sólo protagonizada por la élite caciquil de los "primates", utilizando el término de Joaquín Costa, ni es Madrid su único escenario. Por debajo de esta política de primer orden subyace soterrada, insuficientemente estudiada, toda una infraestructura electoral, toda una sutil red de influencias donde el cacique, el terrateniente, el político de provincias, se hacen imprescindibles para controlar las riendas de la política nacional. Su estudio, pues, se nos antoja del todo necesario.

En este contexto, no cabe duda de que la provincia de Huelva, de la que apenas hay realizados estudios de esta indole, es un marco ideal para el análisis de los comportamientos de la élite política por el fuerte enraizamiento en ella del fenómeno caciquil, y puede aportar ciertas claves de interés.

\section{LA PRENSA Y EL ELECTORADO DE HUELVA ANTE LAS NUEVAS ELECCIONES}

A la altura de 1919, el mecanismo político de la Restauración presenta clarísimos síntomas de «atascamiento". Golpeado por un triple movimiento revolucionario dos años antes y por una opinión pública en estado candente que exige con más fuerza cada vez el destierro de los viejos procedimientos políticos, el sistema se encuentra, si quiere sobrevivir, ante la única alternativa de "una regeneración y un ensanchamiento de las bases democráticas del régimen" ${ }^{2}$. La sinceridad y pureza electoral, marcando una participación efectiva del ciudadano en el trazado político, son conceptos que desde entonces van a ser barajados con insistencia. Numerosas circulares sobre el tema, como la que, procedente de la Fiscalia del Supremo, recoge el diario onubense La Provincia, el 16 de mayo, se hacen habituales.

Sin embargo, cuando con motivo de la contienda electoral de 1919 la vida política comienza a agitarse y se multiplican las promesas de

2 Seco Serrano, Carlos, Alfonso XIII y la crisis de la Restauración. Barcelona, Edit. Ariel, 1969, pág. 116. 
renovación electoral, podemos observar a través de la prensa una incredulidad manifesta sobre la realidad de tales medidas. "Nosotros somos de los que no creen en la posibilidad de sorpresas." Con esta frase, repetida constantemente, o algunas otras como «la suerte está ya echada» y «de las urnas saldrá lo que "debe" salir y nada más», se negaba toda posibilidad de que las votaciones pudieran ser por una vez algo efectivo y se dejaba llevar por la resignación ante un encasillado que consideraba inevitable ${ }^{3}$.

Realmente, las elecciones de 1919, que de partida ofrecían la esperanza de ser un modelo en la eliminación de la influencia corruptora, fueron mostradas en los diarios como lo que con seguridad sería un ejemplo de todo lo contrario. La prensa era consciente de su poder y trató de instrumentalizarlo en defensa de una verdadera renovación de hecho, no sólo de palabra ${ }^{4}$. De ahí lo repetido de sus ataques hacia el mundo político. En otras ocasiones, refiriéndose a la temática de la compra del voto, la crítica se desvía de pronto a los electores, y se llega a decir que «algunos de los cuales no van a los colegios si no se hace lo de siempre» 5 .

La incredulidad o, en algunos casos, la certeza de que las promesas de sinceridad electoral constituian tan sólo una fachada tras la que se ocultaban los fraudes de siempre, se tradujo en Huelva en un retraimiento y una apreciable apatía de la masa electoral. Las palabras de las notas políticas de La Provincia en la víspera de la contienda son bastantes reveladoras: "Todo cuanto a elecciones se refiere se presencia y se realiza con indudable indiferencia, porque lleva en su entraña la esencia del chanchullo.» Esa postura del electorado -que coincide con la progresiva tendencia nacional hacia el abstencionismo con la que Martínez Cuadrado ha querido demostrar el creciente deterioro del sis-

${ }^{3}$ La Provincia, 10 y 26-5-1919. A este respecto pueden ser suficientemente reveladoras las palabras del diario El Liberal de Sevilla del 18-5-1919;

"¿Y usted cree en la verdad y pureza de las próximas elecciones? (...)

Contestación mía:

-A un gitano que estaba confesándose la preguntó el cura:

- ¿Tú crees, hijo, que Dios Nuestro Señor vendrá a la Tierra el día del juicio final para juzgar a los vivos y a los muertos?

- Sí, lo creo, padre. Pero verá usted cómo no viene."

${ }^{4}$ Sobre esta postura mesiánica adoptada por la prensa, que facilitará la descomposición final del sistema, podrá verse, para el caso de Huelva: LaRA Rodenas, J. C., Peña Guerrero, M. A. y Domínguez Domínguez, R. M., "Huelva y la crisis de 1917», Huelva en su Historia, 3, Huelva, Colegio Universitario de La Rábida, (en prensa).

${ }^{5}$ La Provincia, 14 y 26-5-1919. 
tema- ${ }^{6}$ se manifestó en la escasa atención con que éste parece contemplar el "tinglado" electoral en los días de campaña y en la masiva abstención que conoce el día de las votaciones. «Indiferencia», "desanimación», "tranquilidad», son las palabras con las que la prensa describe la jornada del primero de junio en Huelva. Las promesas de pureza electoral, más que activar la participación cuidadana, tuvieron, por su poca credibilidad, un claro efecto de somnífero.

De forma paralela al escepticismo y a las habituales críticas rebosantes de ironía con las que la nueva contienda electoral de 1919 es abordada desde los órganos periodísticos, es posible advertir a través de la prensa la presencia de una corriente de opinión que, crecientemente desde 1917, multiplica sus ataques contra el caciquismo, corriente que no es privativa de Huelva. Efectivamente, y como nos recuerda Javier Tusell, «es precisamente a partir de aquella fecha cuando, a nivel provincial andaluz, adviene una verdadera sublevación contra los caciques, sucediéndose las manifestaciones en contra de los más representativos en cada ciudad o provincia" ?

En los prolegómenos electorales, La Provincia incluyó algunos comentarios significativos al respecto. Reivindicando que las nuevas Cortes habian de ser una cosa bien distinta a las que se habian ido sucediendo anteriormente, decía que "haga las elecciones quien las haga, por fuerza han de ir al Parlamento futuro menos representantes del tradicional y abominable caciquismo, que ya los tiempos no son aquéllos». Por su parte, Alfredo Opisso publicó en el mismo diario un artículo que, titulado "Del Caciquismo", contenía una personal y expresiva definición de esta práctica: «La brutal tiranía de que son víctimas aldeas, pueblos y provincias por parte de personajillos y personajes políticos" ${ }^{8}$. Sin embargo, hasta qué punto la masa ciudadana partició de este malestar que se halla recogido en la prensa es algo bastante difícil de determinar, y posiblemente nunca lleguemos a saberlo con precisión, a pesar de que las alusiones del sevillano diario El Liberal en torno a la opinión pública de Huelva nos quieran presentar un profundo descontento de ésta con respecto al caciquismo ${ }^{9}$.

\footnotetext{
${ }^{6}$ Martinez Cuadrado, Miguel, Elecciones y partidos políticos de España, 1868-1931, Madrid, 1969.

7 Tusell Gómez, Javier, Op. cit., pág. 558.

${ }^{8}$ La Provincia, 10-4-1919 y 6-5-1919.

${ }^{9}$ El Liberal, 2-6-1919.
} 


\section{BURGOS Y MAZO Y EL FRACASO DE LA ALIANZA CONSERVADORA EN LA PROVINCIA: IDÓNEOS CONTRA MAURISTAS}

Cuando, con motivo de las elecciones de 1919, Maura intentó reconstruir desde la presidencia del Gobierno el Partido Conservador llegando a una alianza con los idóneos de Dato, no se le escaparon a este último las innumerables dificultades de orden práctico que en bastantes provincias surgirían si intentasen establecer como obligatorios una serie de principios generales opuestos a las realidades de base. Las dificultades, de hecho, existieron tal y como Dato preveía, y puede ser Huelva una de las provincias que mejor las ejemplifique.

Desde hacía algunos años, como refleja Javier Tusell en Oligarquía y caciquismo en Andalucía (1890-1923), se venía conformando en la provincia un partido conservador paulatinamente más fuerte - «producto de los tropezones de los propios liberales", en palabras de El Liberal- en torno a un hombre de peso específico en la vida política nacional: Manuel de Burgos y Mazo ${ }^{10}$. Creador de un poderoso cacicato personal con epicentro en Moguer, el ex ministro de Gracia y Justicia había imprimido un gran dinamismo y organización al partido conservador de Huelva, partido del que, aun habiendo abandonado su jefatura en beneficio de Francisco Javier Sánchez Dalp, marqués de Aracena, seguía siendo en 1919 su cabeza visible y su jefe espiritual. Esta gran organización del partido acabaría desembocando en una clara hegemonía de los conservadores en la provincia. Concretamente, en las elecciones de 1914, 1916 y 1918 , consiguiendo siempre tres de los cinco escaños que proporcionaba al Parlamento la provincia de Hueva. Estos datos son significativos si tenemos en cuenta que tanto en 1916 como en 1918 fue un Gobierno liberal el que organizó las elecciones ${ }^{11}$. Paulatinamente, los conservadores de Huelva fueron obteniendo una relativa independencia con respecto a Ma-

10 TUSELL Gomez, Javier, Op. cit,, págs. 69 y 70. El Liberal, 2-6-1919. Sobre este respecto, Aguirre Lazareno nos dice en sus biografías de hombres ilustres: «El partido conservador, desde que está dirigido por don Manuel de Burgos, es en Huelva el único, realmente, que como partido político con vida propia existe». (AguiRRE LAZARENO, B., Siluetas de hombre ilustres de Huelva y su provincia. Huelva, 1919, pág. 49).

11 Peña Guerrero, María Antonia, "La élite política de Huelva ante la contienda electoral de 1923". En ofro lugar de este Coloquio. 
drid y, por tanto, la preponderancia provincial a la hora de elaborar los encasillados. Tal fue el caso de las elecciones de $1907^{12}$.

No es de extrañar, por tanto, que cuando se abra la posibilidad de una alianza de idóneos y mauristas, como se planteaba a nivel nacional, todos los ojos vean en Moguer la clave del problema, y se afirme desde las páginas de La Provincia que «todo ocurrirá conforme a los vientos que soplen del simpático pueblo». "El señor Burgos manda. $Y$ a obedecer tocan», se escribirá en otra ocasión ${ }^{13}$.

El encasillado que el Gobierno estableció desde el primer momento para los tres escaños que daba el distrito de la circunscripción - Mora Claros, idóneo; Mora Romero, maurista; y Limón Caballero, liberal romanonista- era del todo lógico en el contexto de la alianza nacional de los conservadores, pero difícilmente podía ser aceptado por los idóneos onubenses. Consciente de su poder, Burgos y Mazo mantuvo desde un principio una negativa «ijreductible» a acatar una alianza que ignoraba por completo la correlación de fuerzas existente en Huelva y venía a repartir los dos diputados que habitualmente le correspondían por la circunscripción con una agrupación, los mauristas, de muy escaso relieve en la provincia $^{14}$.

La negativa a aceptar el encasillado gubernamental —que motivó rumores acerca de la separación del partido de Burgos y Mazo- fue comunicada personalmente a Dato el 13 de mayo por el moguereño ${ }^{15}$. Inmediatamente, el día 16, se reunió el comité provincial de los conservadores bajo al presidencia del marqués de Aracena para realizar la proclamación de sus propios candidatos. La designación de Pedro Luis Casto para luchar por el distrito de Valverde y la sustitución de Manuel Rebollo Orta (al que se le reservó en compensación una senaduría junto a Mariano Vázquez de Zafra) por José Espina Soldán en la circunscripción fueron las principales novedades. Por los demás, Antonio de Mora Claros por este último distrito y Francisco Javier Sánchez Dalp por su «feudo" de Aracena completaron el listado de candidatos. Como venía

12 Tusell Gomez, Javier, Op. cit., pág. 70.

${ }_{13}$ La Provincia, 10 y 14-5-1919 y El Liberal, 17-5-1919.

${ }^{14}$ La Provincia, 28-5-1919.

${ }^{15}$ La Provincia, 12 y 13-5-1919. Acerca de las relaciones entre ambos políticos, Aguirre Lazareno destaca la gran estima en que tenía Dato a Burgos y Mazo, y opina que "no es difícil pensar que sea Burgos y Mazo el sucesor de Dato en la jefatura del partido" (AguiRRE. LazARENo, B., Op. cit, pág. 51). 
siendo habitual, el tercer lugar por la circunscripción se dejó libre a las oposiciones ${ }^{16}$.

Esta postura de Burgos y Mazo, y más aún la sumisión del Gobierno de Maura a los dictados de los idóneos provinciales, provocó un profundo malestar en las filas mauristas de Huelva ${ }^{17}$. De hecho, no asistimos tan sólo al fracaso de la alianza conservadora en la provincia, sino, realmente, a una verdadera inversión de la misma. El 26 de mayo, La Provincia anunció que albistas, socialistas, reformistas y mauristas irían unidos a las elecciones, lo que venía a ser "algo así como un "trágala" para el Gorbierno". Ante esta postura de abierta hostilidad maurista, la reacción de los idóneos y del propio Gobierno no se dejó esperar. Pero, mejor que nosotros, dejemos que sea el diario La Provincia, en su número del 27 de mayo, el que nos la ponga de manifiesto:

«La tempestad estalló en forma de protestas que salieron de Huelva o de cualquier pueblo vecino para Madrid, protestas que debieron ser tan eficaces que determinaron allá en la corte una conferencia del señor Dato con el ministro de la Gobernación y, como consecuencia de ella, un telegrama del señor Goicoechea al gobierno de nuestra capital redactado en forma tan terminante y clara que los que de él tuvieron conocimiento quedáronse turulatos y como si les hubiesen echado un jarro de agua helada».

Al abordar el tema de la retirada del maurista Manuel Fernández Balbuena, que se presentaba por el distrito de Valverde, el diario continuaba diciendo:

«¿Qué había ocurrido para que tal decisión fuese adoptada por el candidato maurista, el cual estaba tan animado horas antes para dar la batalla a las huestes enemigas?

Se decía que el telegrama ministerial era tan explícito que en él se conminaba a los mauristas onubenses para abstenerse en absoluto de ir a la lucha so pena de hacerlo por su cuenta y riesgo sin más fuerza que la propia.

${ }^{16}$ La Provincia, 16-5-1919. Burgos y Mazo intentó colocar a su hijo, Manuel de Burgos Domínguez, como candidato por la circunscripción, pero éste hubo de retirarse (La Provincia, 14-5-1919).

17 Algunos mauristas de Huelva llegan a decir: «Estamos todos contra el caciquismo de Burgos. ¿Qué se ha creído el pontífice de Moguer?" (E/ Liberal, 22-5-1919). 
Se decía que el disgusto de los datistas se había tracado en regocijo contrastando con la desilusión hosca de los mauristas, acatando a regañadientes el ukase ministerial, sin curarse de la disciplina se habían reunido en un momento de rebeldía para exteriorizar ésta en un acto de trascendencia».

El comentario, aunque extenso, merce la pena ser reproducido. Es un expresivo relato del enfrentamiento entre las dos corrientes conservadoras en Huelva, «la única provincia de España donde el Gobierno no tiene predicamento" ${ }^{18}$. Los idóneos, de esta manera, se reservaban la posibilidad de vencer al republicano Barriobero y conseguir, así, un cuarto escaño por la provincia. Por lo demás, en el citado "acto de trascendencia» se decidió la abstención maurista en la convocatoria electoral y se propuso, por parte de algunos de sus elementos más caracterizados, la disolución del comité del partido en la provincia, "ya que no servía ni para imponer como candidato a un amigo que se proponía luchar por un distrito con posibilidades de lucha". La propuesta, finalmente, no tuvo otra consecuencia que la separación del partido de Quitero Báez y de los hermanos Carlos y Fenando Rey ${ }^{19}$, con lo que los mauristas de Huelva, que ya de por sí formaban un grupo reducido, se adentraron en un intenso período de crisis ${ }^{20}$.

La resistencia de Burgos y Mazo a aceptar un pacto con los mauristas sobrepasó al momento electoral y al propio ámbito de la provincia. Cuando, a mediados de junio, circule el rumor de que una crisis iba a sellar la alianza dejando tres ministerios libres para los datistas, el moguiereño se opondrá de una manera clara y rotunda ${ }^{21}$.

\section{LA COMPLEJIDAD DEL ENCASILLADO: LAS RESTANTES FUERZAS POLITICAS}

Eclipsadas por la problemática de la resistencia de los conservadores idóneos provinciales a aceptar una alianza con los mauristas, las

${ }^{18}$ La Provincia, 28-5-1919.

19 Quintero y los hermanos Carlos y Fernando Rey formarán parte, posteriormente, de los cuadros políticos de la dictadura (Peña Guerrero, M. A., Op. cit.).

${ }^{20}$ La Provincia, 28-5-1919.

${ }^{21}$ La Provincia, 16-6-1919. 
Política y lucha de partidos en la Huelva de la Restauración ...

evoluciones de las restantes fuerzas políticas en el escenario electoral de 1919 parecen cobrar una menor relevancia. Sin embargo, con la presencia de sus candidatos en los tres distritos de la provincia de Huelva y con el establecimiento de algunos pactos electorales, contribuyeron a ir complicando la elaboración de un encasillado que, ya por parte conservadora, presentaba serias dificultades.

Ahora bien, un elemento en este rompecabezas sí que quedaba claro desde un principio: aceptado tanto por el Gobierno de Madrid como por el partido conservador datista de Huelva -hegemónico en la provincia-, José Limón Caballero, jefe provincial de los liberales romanonistas, ocuparía el tercer escaño de la circunscripción junto a los dos conservadores (ya fuesen dos idóneos o uno idóneo y uno maurista), tal y como sucedió en 1918. De esta manera, la rama romanonista de los liberales - «fuerza grande y disciplinada», en palabras de Aguirre Lazareno ${ }^{22}$ consolidaba su predominio en la provincia frente a los albistas, si bien demostraba a las claras la gran inferioridad liberal con respecto a unos conservadores que, sumando el escaño «vitalicio» de Sánchez Dalp por Aracena, obtendrían tres diputados por cuarta vez consecutiva.

La creciente fortaleza de los datistas, que amenazaban con absorber todo el panorama político provincial, y el gran debilitamiento liberal pueden quedar suficientemente manifestados si consideramos que los conservadores, presentando a Pedro Luis Casto Ramírez, "hijo del distrito", intentarían alcanzar un cuarto escaño luchando en el distrito de Valverde contra el republicano Eduardo Barriobero -usando en última instancia, aunque infructuosamente, el recurso del pucherazo- y que para ello contarían con el apoyo romanonista, a pesar de que su candidato de 1918, Juan Gómez Acebo, pensaba en luchar e hizo «desde Madrid cuanto pudo por captarse las simpatías de sus futuros electores» ${ }^{23}$. En cualquier caso, Barriobero logró finalmente revalidar el acta de diputado conseguido en las elecciones anteriores, confirmando así el ascenso republicano en la cuenca minera que siguió a la huelga general de 1917.

Eduardo Barriobero Herrán, jefe del republicanismo onubense y al que la prensa daba como seguro triunfador por Valverde ${ }^{24}$, fue recorriendo las localidades del distrito desde mediados del mes de mayo, demostrando así que los republicanos seguían siendo los más dinámicos

${ }^{22}$ Aguirre lazareno, B., Op. cit., pág. 88. En otra ocasión se refiere a los romanonistas como a «una robusta fracción política" (pág. 87).

${ }^{23}$ La Provincia, 10-5-1919 y El Liberal, 31-5-1919.

${ }^{24}$ El Liberal, 31-5-1919. 
y activos en las campañas electorales que se desarrollaban en la provincia ${ }^{25}$. El hecho de que los albistas, en la reunión de su comité provincial, acordaran apoyar a los republicanos en Valverde, aportó una «inusitada animación» a la contienda, viniendo a establecer una lucha entre dos alianzas: datistas-romanonistas contra republicanos-albistas ${ }^{26}$. En realidad, el distrito de Valverde fue el único en el que se planteó una verdadera confrontación reñida. En el resto de los casos, las izquierdas tan sólo se limitaron a impedir, con su presencia, la aplicación del artículo 29:

"Lo malo es, para los datistas, que ya se las prometían felices y hasta soñaban con el artículo 29, que ahora, por virtud de unos cuantos señores que no están de buenas, habrá que montar el tinglado electoral ${ }^{27}$.

Efectivamente, los liberales albistas, que contaban «con las simpatías de los representantes republicanos, socialistas y otros elementos avanzados por la gallarda actitud en que se hallan colocados", quisieron dar la batalla en todos los distritos. Guillermo Moreno Calvo, antiguo jefe de los liberales de Huelva y al frente, en 1919, de los albistas, recibió del comité provincial un amplio voto de confianza para que designara los candidatos. Los elegidos fueron Cándido Romero Martín por Aracena y Nicolás Vázquez de la Corte y José Coto Mora por la circunscripción, que se encargaron, en la medida de sus escasas posibilidades, de «amenizar» al menos la jornada electoral ${ }^{28}$.

Sin lugar a dudas, uno de los grandes ausentes de la contienda electoral de 1919 fue José Tejero G. Vizcaíno. Diputado liberal en 1914 por uno de los tres escaños de la circunscripción, Tejero derivó hacia una posición independiente. Aunque, desde un principio, la prensa lo nombró entre los candidatos de 1919, este «revolucionario temperamen-

${ }^{25}$ El Liberal, 18-5-1919. Sobre el habitual dinamismo de los republicanos, viene recogida alguna información en Lara Rodenas J. C., Peña Guerrero M. A. y Dominguez DominGUEZ R. M., Op. cit.

${ }^{26}$ Esta alianza perdurará. En la reunión de republicanos y socialistas del día 15 de junio de 1919 se acordó acudir a las elecciones de diputados provinciales «en inteligencia con los elementos albistas de la provincia para combatir y desterrar la nefasta política caciquil del señor Burgos" (La Provincia, 16-6-1919).

${ }_{27}$ La Provincia, 26-5-1919.

28 El Liberal, 20,22 y $31-5-1919$. 
tal» anunció su retirada a través de una carta que dirigió a los lectores desde las páginas de La Provincia. En ella, justificando su decisión, puso de relieve el sacrificio que la representación parlamentaria le supondría ante un «poder público yacente en el arroyo y mordido por las peores concupiscencias del odioso feudalismo político" 29.

\section{EL DESARROLLO DE LA JORNADA ELECTORAL. LA GRAN VITALIDAD DE LOS VIEJOS PROCEDIMIENTOS}

"La evolución de las elecciones desde 1891 hasta 1931 pueden ser definidas como una sucesión de esperanzas defraudadas. En cada uno de esos períodos en los cuales se ha dividido la historia electoral del reinado de Alfonso XIII existían motivos e incluso indicios para que se pudiera pensar en una inmediata regeneración política del país que condujera a su independencia electoral. Sin embargo, no hay duda de que, en sus líneas generales, el sistema (...) sigue vigente».

Sin lugar a dudas, las esperanzas defraudadas que Javier Tusell extiende a todo el período de la Restauración se hicieron sentir con un peso propio en la contienda electoral de 1919. Efectivamente, si difícil es encontrar un momento en el que esos indicios de regeneración política, traducidos en promesas de sinceridad electoral, tomaran un cuerpo tan consistente como en este año, más lo es, si cabe, encontrar un ejemplo de corrupción mayor como la habida en la geografía andaluza con motivo de la nueva convocatoria electoral ${ }^{30}$.

La provincia de Huelva, en este sentido, no fue ninguna excepción. Por el contrario, podemos hallar en el transcurso de la jornada del primero de junio un verdadero muestrario de las técnicas de manipulación electoral de la vieja política. Coincidiendo con un período de generalizada compra del voto ${ }^{31}$, es éste uno de los procedimientos que alcanzaron en Huelva un carácter de verdadero protagonismo. Referencias a la «esplen-

${ }^{29}$ La Provincia, 20-5-1919. Estas vigorosas palabras parecen corresponder perfectamente al carácter que Aguirre Lazareno le atribuye en su biografía: «Uno de esos hombres nerviosos, cenceños, impulsivos, generosos y fieros que parecen recortados de un aguafuerte de Goya". Aguirre Lazareno, B., Op. cit., pág. 199).

30 TuSELl GoMEZ, Javier, Op. cit., págs. 562 y 575.

31 Ibidem, pág. 139. 
didez» de un determinado político o a electores de «los de a duro el voto" son fáciles de encontrar en la prensa. Por lo demás, en la víspera de la contienda, La Provincia incluye un párrafo ciertamente revelador sobre la compra del voto, práctica, por cierto, que no se llevaba precisamente en secreto:

"En las elecciones de mañana, según se afirma vox populi, se hace gala por los candidatos, en conversaciones públicas, y es objeto del general comentario el coste de la compra de los distritos.

¿No es esto desmoralizar por completo a los ciudadanos en el orden político?".

El grado de corrupción advertido por la prensa a lo largo de los prolegómenos electorales puede, del mismo modo, advertirse en este expresivo y jocoso comentario de La Provincia:

«Qué elecciones!

Éstas que vamos a presenciar el domingo van a dejar en pañales a las que hacía Romero Robledo. Yo, para encontrarles precedente, sólo recuerdo aquellas otras en que el Gobierno envió a Écija dos regimientos y un tercio de la Guardia Civil para derrotar a don Nicolás María Rivero" ${ }^{32}$.

Sin embargo, hay que esperar hasta la propia jornada electoral para encontrarnos con la verdadera oleada de fraudes. Ningún tipo de procedimiento parece faltar: en el distrito de Aracena no se dio posesión en los colegios electorales a los interventores albistas por temor a «inesperados resultados" que hicieran peligrar el acta de Sánchez Daip; en Santa Ana la Real se cerraron los colegios a las tres, dándose por terminadas las elecciones antes de tiempo; en Villanueva de las Cruces ni siquiera se abrieron; en la circunscripción de Huelva se dio la constitución ilegal de las mesas en numerosos pueblos, se utilizó un nuevo censo en el que figuraban muertos y ausentes, quedando eliminadas personas conocidas, y los funcionarios $-y$ sabida es la presión que se ejercía sobre

32 La Provincia, 28-5-1919. 
ellos para que votaran la candidatura oficial- fueron los únicos que se acercaron a las urnas en una jornada en la que dominó la abstención ${ }^{33}$.

No obstante, fue lo que se dio en llamar el «milagro de Puebla de Guzmán» el suceso que acaparó la atención de la prensa en los días posteriores ${ }^{34}$. Consistió en un verdadero pucherazo a la antigua. El hecho de que Eduardo Barriobero Herrán, el líder republicano de Huelva, contaba con todos los pronunciamientos para alzarse con el acta de diputado por el distrito de Valverde, tal y como sucedió en la convocatoria de 1918, era algo conocido por todos. Su principal adversario, el datista Pedro Luis Casto, se enfrentaba, realmente, con una misión imposible. Desde que, finalizadas las votaciones, que arrojaban clara mayoria para Barriobero - 5745 votos frente a 5117 - los resultados de Puebla de Guzmán comenzaron a hacerse esperar, numerosas versiones - «para todos los gustos»- fueron circulando por la opinión pública, algunas de las cuales "ni el censor más complaciente del mundo dejaría pasar». Cuando, al fin, llegaron los datos, el escándalo fue unánime: la práctica totalidad del censo había votado en favor del candidato datista, lo que suponía un auténtico vuelco de los resultados. Lo grave no era, ciertamente, la radical inversión del balance de un año antes ${ }^{35}$, sino que, "como lo vieron hasta los ciegos», en realidad nadie había podido votar en Puebla de Guzmán por la «repentina» enfermedad de los presidentes y adjuntos de los colegios electorales. En cualquier caso, el recurso presentado por Eduardo Barriobero prosperó, y el partido republicano pudo revalidar así el escaño conseguido el año anterior.

${ }^{33}$ La Provincia, 2 y 5-6-1919 y El Liberal, 2-6-1919.

${ }^{34}$ La Provincia, 5 y 27-6-1919 y El Liberal, 3, 4 y 5-6-1919. El día 4 de junio circuió, incluso, una hoja extraordinaria del diario República comentando los incidentes ocurridos en las elecciones del distrito de Valverde (La Provincia, 4-6-1919).

${ }^{35}$ En las elecciones de febrero de 1918, Eduardo Barriobero obtuvo, en Puebla de Guzmán, 180 votos frente a los 53 de Juan Gómez Acebo, liberal romanonista. En junio de 1919, Barriobero 10 votos frente a 838 de Pedro Luis Casto, conservador datista. Boletín Oficial de la Provincia de Huelva, 27-2-1918 y 3-6-1919. 